\title{
Simvastatin attenuates Trinitrobenzene sulfonic acid-induced colitis, but not
}

\section{Oxazalone-induced colitis}

Maho Ikeda, Fuminao Takeshima*, Hajime Isomoto, Saburo Shikuwa, Yohei Mizuta,

Yoshiyuki Ozono, Shigeru Kohno

Second Department of Internal Medicine and *Department of General Medicine, Nagasaki

University School of Medicine, Nagasaki,

Running title: Simvastatin protects against TNBS colitis

Key words: Simvastatin, statin, TNBS, colitis

Corresponding author:

Fuminao Takeshima, MD, PhD.

Department of General Medicine,

1-7-1 Sakamoto

Nagasaki 852-8501, Japan

Email: ftake@net.nagasaki-u.ac.jp

Phone: +81-(0)95-849-7591

Fax: +81-(0)95-849-7597 


\section{Abstract:}

Purpose: To determine whether simvastatin is able to inhibit inflammation in trinitrobenzene sulfonic acid (TNBS)-induced or oxazalone (OXA)-induced colitis.

Results: In the prophylactic protocol, simvastatin dose-dependently suppressed the decrease in body weight and inflammatory grade of TNBS-treated mice. In contrast, in the therapeutic protocol, no significant difference in body weight reduction was observed between simvastatin-treated and control mice. IFN- $\gamma$ release from LP cells was significantly suppressed in mice receiving high-dose simvastatin in the prophylactic protocol. In contrast to TNBS colitis, even high-dose prophylactic simvastatin had no suppressive effects on either weight reduction or inflammatory grade in OXA colitis.

Conclusion: Our results indicate that simvastatin negatively regulates inflammation in TNBS-induced colitis but not in OXA-induced colitis. In TNBS-induced colitis, simvastatin suppressed the Th1-polarized immune response. Our findings suggest that simvastatin has potential effects as a therapeutic agent in human inflammatory bowel disease, particularly Crohn's disease. 


\section{Introduction:}

Statins are known to be 3-hydroxy-3-methylglutaryl coenzyme A (HMG-CoA) reductase inhibitors, and are widely used to reduce cholesterol in patients with hyperlipidemia leading to cardiovascular morbidity (1). Recent clinical studies have suggested that statins may also have immunosuppressive effects and be useful in the treatment of inflammatory diseases. For example, clinical trials have demonstrated that simvastatin and pravastatin have an effect on the prevention of transplant rejection after heart transplantation $(2,3)$. Statins also reduced high sensitive C-reactive protein levels $(4,5)$ and vascular proinflammatory cytokines, such as TNF- $\alpha$, IL-1 and IL-6 (6) in hyperlipidemia patients.

Although the molecular mechanisms of such anti-inflammatory activities remain unclear, recent studies have provided some insight. Certain statins are able to inhibit the interaction between LFA-1 and ICAM-1 (7). Moreover, statins also prevented IFN inducible MHC class 2 expression in non-professional APC (8). In vivo, using murine models, Youssef et al. (9) demonstrated that atorvastatin rescued experimental Th1 encephalomyelitis, inhibiting the Th1-mediated immunoresponse. Leung et al. (10) also reported an anti-inflammatory role for simvastatin in experimental Th1 arthritis. Recently, it was reported that simvastatin reduced the expected number and volume of new gadolinium-enhancing lesions in relapsing-remitting multiple sclerosis patients in a small open label trial (11). Atorvastatin has also been reported to decrease the disease score and vascular risk factors in patients with rheumatoid arthritis in a double-blind placebo controlled trial (12).

Based on these results, statins appear to be beneficial for other Th1-mediated autoimmune diseases. Human inflammatory bowel disease (IBD), such as Crohn's disease (CD) and ulcerative colitis (UC), are believed to be autoimmune conditions resulting from an abnormal mucosal $\mathrm{T}$ cell response to bacteria in the lumen. In $\mathrm{CD}$, mucosal $\mathrm{T}$ cells exhibit 
Th1 phenotype, whereas ulcerative colitis is believed to have Th2 phenotype, but this has not been clearly demonstrated. Three recent articles have shown that pravastatin (13), rosuvastatin (14) and simvastatin (15) are able to reduce disease activity and colonic inflammation in dextran-sulfate (DSS)-induced colitis in mice.

Trinitrobenzene sulfonic acid (TNBS)-induced colitis is a colitis model that results in transmural infiltration and an IL-12-driven, Th1-mediated response $(16,17)$. In contrast, oxazalone (OXA)-induced colitis is caused by a polarized Th2-mediated response (16). We can thus utilize both TNBS-induced and OXA-induced murine experimental colitis as models of human IBD in order to test whether statins are able to suppress such colitis. The present study was conducted in order to elucidate whether statins can inhibit the inflammation of TNBS-induced or OXA-induced colitis

\section{Methods:}

Animals All experiments were performed in accordance with the Guidelines for Animal Experimentation of Nagasaki University. Six- to eight-week-old SJL/J male mice were obtained from SLC Inc (Shizuoka, Japan).

Experimental colitis models Colitis was induced in SJL/J mice as described previously $(18,19)$. Briefly, in order to presensitize mice, abdominal skin was shaved and $150 \mu 1$ of either TNBS $(2.5 \%$ in $50 \%$ ethanol) or OXA ( $3 \%$ in $100 \%$ ethanol) was applied. Five days after presensitization, mice were intrarectally administered $150 \mu$ of a solution of $1.5 \%$ TNBS or $1 \%$ OXA dissolved in $0.9 \% \mathrm{NaCl}$ and mixed with an equal volume of ethanol. Control mice $(\mathrm{CO})$ were given ethanol in place of TNBS.

Treatment protocols For the prophylactic protocol, mice were administered $10 \mathrm{mg} / \mathrm{kg}$ or $40 \mathrm{mg} / \mathrm{kg}$ i.p. simvastatin daily from 5 days before to 7 days after rectal administration of TNBS or OXA. For the therapeutic protocol, mice were administered $10 \mathrm{mg} / \mathrm{kg}$ or $40 \mathrm{mg} / \mathrm{kg}$ i.p. simvastatin daily for a total 7 days after rectal administration of TNBS or OXA. Control 
mice (NS) for simvastatin treatment received $0.9 \% \mathrm{NaCl}$ in place of simvastatin.

Histological grading of colitis Sections of the proximal, middle, and distal colon were fixed in $3 \%$ buffered formalin. Tissue sections were subjected to hematoxylin and eosin staining using standard techniques for histological examination. Degree of inflammation was graded semiquantitatively, as described previously (17). The grading system was as follows: $0=$ no inflammation; $1=$ very low-level inflammation; $2=$ low-level inflammation; $3=$ high-level inflammation with high vascular density and thickening of the colon wall; and $4=$ transmural infiltration with loss of goblet cells, high vascular density and thickening of the colon wall. Grading was performed in blinded fashion.

Isolation of lamina propria (LP) cells Colons were washed with PBS and were digested with dispase (2 mg/ml, Gibco BRL, Grand Island, NY) at $37^{\circ} \mathrm{C}$ for 1 hour in complete media (RPMI 1640 media supplemented with 4\% FCS, 2 mM L-glutamine, 10 mM HEPES, 100 $\mathrm{U} / \mathrm{ml}$ penicillin, $100 \mu \mathrm{g} / \mathrm{ml}$ streptomycin and $250 \mathrm{ng} / \mathrm{ml}$ amphotericin) in order to remove the epithelial compartment, including intraepithelial lymphocytes. Samples were then minced into small pieces and further digested with collagenase (1 mg/ml, Gibco BRL) and dispase (2 $\mathrm{mg} / \mathrm{ml}$ ) for another hour at $37^{\circ} \mathrm{C}$. After washing, cells were purified using the $40 \% / 70 \%$ Percoll gradient method to remove epithelial and dead cells. Cells at the interface were isolated and washed with PBS.

Analysis of cytokine production Colonic LP cells were cultured at $2 \times 10^{5}$ cells in $150 \mu 1$ of media (DMEM/F-12 Media containing 1\% FCS, $100 \mathrm{U} / \mathrm{ml}$ penicillin, $100 \mu \mathrm{g} / \mathrm{ml}$ streptomycin, $250 \mathrm{ng} / \mathrm{ml}$ amphotericin, $2 \mathrm{mM}$ L-glutamine, $0.05 \mathrm{mM}$ 2ME, $10 \mathrm{mM}$ HEPES, $1 \mathrm{mM}$ sodium butyrate and 1x SITE-3). Cells were either unstimulated or stimulated with anti-TCR- $\beta$. Supernatant was collected after five days of culture, spun down for cell removal, and frozen at $-80^{\circ} \mathrm{C}$ until cytokine analysis. OptEIA ${ }^{\mathrm{TM}}$ cytokine sandwich ELISA kits from PharMingen were used to assess the expression of IL-4, IL-5, IFN- $\gamma$ and TNF- $\alpha$, in 
accordance with the manufacturer's instructions.

Statistical analysis All data are expressed as means \pm SEM. Differences between groups were examined for statistical significance using Student's $t$-test. A $P$ value of less than 0.05 denoted the presence of a statistically significant difference.

\section{Results}

Simvastatin prevents mice from developing TNBS colitis In order to determine whether simvastatin suppresses immune-mediated pathology in vivo, we investigated the effects of simvastatin in TNBS-induced colitis (prophylactic protocol). As shown in Figure 1, SJL/J mice treated with TNBS alone (NS) manifested a severe illness characterized by weight loss and diarrhea peaking on day 4 after intrarectal administration of TNBS. A significant decrease in body weight $(15.1 \pm 1.4 \%$; $\mathrm{n}=20)$ was seen in TNBS-treated mice in comparison with the CO group (ethanol-treated mice). Simvastatin dose-dependently suppressed the decrease in body weight in TNBS-treated mice. Administration of high-dose (40 mg/day) simvastatin, but not low-dose (10 mg/day) simvastatin, reduced the decrease in body weight $(6.6 \pm 2.0 \%, \mathrm{n}=19$ vs. $16.4 \pm 1.8 \%, \mathrm{n}=6$, respectively; $\mathrm{p}<0.01$, high-dose simvastatin in comparison with NS). On macroscopic examination (Figure 2), while NS colons showed severe colitis involving the entire colon and shortening of colon length, colons from high-dose simvastatin-treated TNBS mice were similar in appearance to those from CO mice. In addition, as shown in Figure 3a, on microscopic examination, NS colons revealed transmural inflammation involving all layers of the bowel wall with numerous granulocytes, monocytes and lymphocytes. Conversely, the colons from high-dose simvastatin-treated TNBS mice were almost free of colitis. Inflammatory grade was also markedly improved in high-dose simvastatin-treated TNBS mice in comparison with NS mice $(1.4 \pm 0.3, \mathrm{n}=14$ vs. $2.9 \pm 0.2, \mathrm{n}=17 ; \mathrm{p}<0.001)$ (Figure $3 \mathrm{~b})$. 
We then investigated the effects of simvastatin after onset of TNBS-induced colitis (therapeutic protocol). No significant differences in body weight reduction were observed between simvastatin-treated (therapeutic protocol) and NS mice (Figure $4 ; 12.9 \pm 2.3 \%, \mathrm{n}=11$ vs. $12.8 \pm 2.0 \%, \mathrm{n}=13$ ). With regard to inflammatory grade, the mean score in simvastatin-treated (therapeutic protocol) TNBS mice was significantly lower than that in NS mice significantly (Figure $5 ; 2.3 \pm 0.2, \mathrm{n}=11$ vs. $3.0 \pm 0.2, \mathrm{n}=13 ; \mathrm{p}<0.05$ ).

Simvastatin suppresses Th1 cytokine production in TNBS colitis The cytokine profile of $\mathrm{T}$ lymphocytes in TNBS-induced colitis was investigated by stimulating colonic LP cells from NS mice via the antigen receptor (anti-TCR- $\beta$ ) and analyzing cytokine expression in the supernatants. As expected, colonic LP cells from NS mice produced large amounts of Th1 cytokines (IFN- $\gamma$ and TNF- $\alpha$ ) upon antigen-receptor stimulation (Figure 6). In contrast, very little production of IL-4 or IL-5 was detected. Next, we investigated whether simvastatin (prophylactic protocol) suppresses the Th1-polarized immune response induced by TNBS. IFN- $\gamma$ release upon antigen-receptor stimulation was significantly suppressed in mice receiving high-dose simvastatin (simvastatin, $115.9 \pm 36.6 \mathrm{pg} / \mathrm{ml}, \mathrm{n}=8$ vs. NS, $436.8 \pm 51.2$ $\mathrm{pg} / \mathrm{ml}, \mathrm{n}=7 ; \mathrm{p}<0.001)$. TNF- $\alpha$ release upon antigen-receptor stimulation was lower in mice receiving high-dose simvastatin than in NS mice, but this difference was not significant $(193.2 \pm 29.6 \mathrm{pg} / \mathrm{ml}, \mathrm{n}=8$ vs. $312.9 \pm 60.8 \mathrm{pg} / \mathrm{ml}, \mathrm{n}=7 ; \mathrm{p}=0.11)$.

Simvastatin did not prevent mice from developing OXA colitis In order to determine whether simvastatin suppresses another immune-mediated colitis model, we investigated the effects of simvastatin on the development of OXA-induced colitis, which is caused by a polarized Th2-mediated response. In contrast to TNBS colitis, even high-dose simvastatin (prophylactic protocol) had no suppressive effects on either weight reduction (Figure 7a; simvastatin, $13.3 \pm 1.5 \%, \mathrm{n}=19$ vs. NS, $15.5 \pm 1.1 \%, \mathrm{n}=20 ; \mathrm{p}=0.27$ ) or inflammatory grade (Figure $7 b ; 2.8 \pm 0.2 \%, n=19$ vs. $3.2 \pm 0.2, n=20 ; p=0.39$ ) 


\section{Discussion:}

In the present study, we provide experimental evidence that simvastatin negatively regulates the inflammatory response in TNBS-induced colitis. Moreover, we demonstrated that prophylactic administration is more effective than therapeutic administration in treating TNBS-induced colitis. TNBS-induced colitis is hapten-induced model of human IBD. Intestinal inflammation in this model does not result from the direct effects of this chemical, but rather from delayed hypersensitivity to TNBS-modified self-antigens. The highly prophylactic effects of simvastatin on the development of TNBS-induced colitis suggest that statins may suppress not only acute inflammation, but also immune-mediated pathology.

Recently, special attention has paid to the effect of statins on rodent colitis models. Sasaki et al. (13) reported that pravastatin relieved DSS-induced acute colitis in mice and promoted colonic endothelial nitric-oxide synthase (eNOS) mRNA expression. That study also demonstrated that the protective effects of pravastatin were not present in eNOS-deficient mice. Similarly, Naito et al. (14) demonstrated that rosuvastatin suppresses intestinal inflammation and inhibits the increase in TNF- $\alpha$, and the decrease in eNOS in DSS-induced acute colitis in mice. Lee et al. (15) showed that simvastatin inhibited TNF- $\alpha$-induced IL-8 gene expression and nuclear transcription factor $\kappa B(\mathrm{NF}-\kappa \mathrm{B})$ transcriptional activity in intestinal epithelial cells. That study also showed that simvastatin prevents DSS-induced acute colitis in mice. Suzuki et al. (20) reported that fluvastatin inhibits colonic inflammation and incidence of colorectal dysplasia in DSS-induce chronic colitis in mice. Jahovic et al. (21) demonstrated that simvastatin and fluvastatin reduces colonic inflammation and serum TNF- $\alpha$ levels in TNBS-induced colitis in rats. These results, taken together with those of the present study, suggest that statins are potential therapeutic agents for human IBD. 
Several studies $(22,23)$ have demonstrated that statins can promote protective $\operatorname{Th} 2$ development and inhibit Th1 development in rodent models of Th1-mediated autoimmune disease. Liu et al. (22) demonstrated that atorvastatin ameliorates experimental autoimmune myocarditis, which is related to Th1 responses, accompanied by reductions in IFN- $\gamma$ and IL-2 and the promotion of IL-4 and IL-10 production. Similarly, Aprahamian et al. (23) demonstrated that simvastatin reduces serum TNF- $\alpha$ and IFN- $\gamma$ levels and increases IL- 4 and IL-10 transcript levels in lymph nodes in a murine lupus model. In vitro, Arora et al. (24) demonstrated that simvastatin-treated murine dendritic cells promote T cells to secret IL-4, IL-5 and IL-13, and this cytokine secretion profile was correlated with increased expression GATA-3 and decreased expression of T-bet by T cells.

Although CD and UC share clinical and pathological characteristics, each has a distinct cytokine production profile. CD is a Th1-mediated inflammatory disease $(25,26)$. Various studies have shown predominant synthesis of IL-12 by macrophages and IFN- $\gamma$ by T cells. In addition, mucosal lymphocytes in CD express high levels of active STAT-4, which is activated by IL-12 receptor signals and is necessary for the induction of Th1-associated genes. In this study, we used TNBS-induced colitis as a model of CD, and demonstrated that simvastatin suppresses the Th1-polarized immune response induced by TNBS, similarly to other Th1-mediated autoimmune animal models.

On the other hand, based on various reports, such as the association between UC and the production of autoantibodies as well as the increased secretion of the Th2-related immunoglobulin subclasses IL-5 and IL-13, UC is believed to be a Th2-mediated inflammatory disease (25). In this study, we used OXA-induced colitis as a model of UC but simvastatin did not show any suppressive effects on either weight reduction or inflammatory grade in this model. In support of these results, there is a single case report of UC after pravastatin treatment (27). The authors speculated that statins may reveal previously 
quiescent UC in susceptible individuals. There are several reports on other Th2-mediated autoimmune diseases. Mckay et al. (28) demonstrated that simvastatin reduces IL-4 and IL-5 production in bronchoalveolar lavage fluid in a murine model of allergic asthma. In contrast, a randomized double blind crossover trial (29) did not find any anti-inflammatory effects of simvastatin in patients with asthma. Based on the results regarding the effects of statins in promoting Th2-bias (22-24), as well as the present data, the use of statins in Th2-mediated autoimmune disease must be evaluated cautiously. iesFurther basic and clinical stud Further basic and clinical studies assessing the effects of statins on Th2-mediated autoimmune disease are thus necessary.

In conclusion, we demonstrated that simvastatin negatively regulates inflammation in TNBS-induced colitis, but not in OXA-induced colitis. In TNBS-induced colitis, simvastatin suppressed a Th1-polarized immune response. Our findings suggest that simvastatin has potential effects as a therapeutic agent in human IBD, particularly CD.

\section{Acknowledgements}

We would like to thank Merck \& Co., Inc. for providing simvastatin. 
References

1. Amarenco P, Labreuche J, Lavallée P,Touboul PJ:Statins in stroke prevention and carotid atherosclerosis: systematic review and up-to-date meta-analysis. Stroke $35: 2902-2909,2004$

2. Wenke K, Meiser B, Thiery J, Nagel D, von Scheidt W, Steinbeck G, Seidel D, Reichart B:Simvastatin reduces graft vessel disease and mortality after heart transplantation: a four-year randomized trial. Circulation 96:1398-1402,1997

3. Mehra MR, Uber PA, Vivekananthan K, Solis S, Scott RL, Park MH, Milani RV,Lavie CJ:Comparative beneficial effects of simvastatin and pravastatin on cardiac allograft rejection and survival. J Am Coll Cardiol 40:1609-1614,2002

4. Ridker PM, Rifai N, Clearfield M, Downs JR, Weis SE, Miles JS,Gotto AM:Measurement of $\mathrm{C}$-reactive protein for the targeting of statin therapy in the primary prevention of acute coronary events. N Engl J Med 344:1959-1965,2001

5. Jialal I, Stein D, Balis D, Grundy SM, Adams-Huet B,Devaraj S:Effect of hydroxymethyl glutaryl coenzyme a reductase inhibitor therapy on high sensitive $\mathrm{C}-$-reactive protein levels. Circulation 103:1933-1935,2001

6. Ascer E, Bertolami MC, Venturinelli ML, Buccheri V, Souza J, Nicolau JC, Ramires JA,Serrano CV:Atorvastatin reduces proinflammatory markers in hypercholesterolemic patients. Atherosclerosis 177:161-166,2004

7. Weitz-Schmidt G, Welzenbach K, Brinkmann V, Kamata T, Kallen J, Bruns C, Cottens S, Takada Y,Hommel U:Statins selectively inhibit leukocyte function antigen-1 by binding to a novel regulatory integrin site. Nat Med 7:687-692,2001 
8. Kwak B, Mulhaupt F, Myit S,Mach F:Statins as a newly recognized type of immunomodulator. Nat Med 6:1399-1402,2000

9. Youssef S, Stüve O, Patarroyo JC, Ruiz PJ, Radosevich JL, Hur EM, Bravo M, Mitchell DJ, Sobel RA, Steinman L,Zamvil SS:The $\mathrm{HMG}^{-} \mathrm{CoA}$ reductase inhibitor, atorvastatin, promotes a Th2 bias and reverses paralysis in central nervous system autoimmune disease. Nature 420:78-84,2002

10. Leung BP, Sattar N, Crilly A, Prach M, McCarey DW, Payne H, Madhok R, Campbell C, Gracie JA, Liew FY,McInnes IB:A novel anti-inflammatory role for simvastatin in inflammatory arthritis. J Immunol 170:1524-1530,2003

11. Vollmer T, Key L, Durkalski V, Tyor W, Corboy J, Markovic-Plese S, Preiningerova J, Rizzo M,Singh I:Oral simvastatin treatment in relapsing-remitting multiple sclerosis. Lancet 363:1607-1608,2004

12. McCarey DW, McInnes IB, Madhok R, Hampson R, Scherbakov O, Ford I, Capell HA,Sattar N:Trial of Atorvastatin in Rheumatoid Arthritis (TARA): double-blind, randomised placebo-controlled trial. Lancet 363:2015-2021,2004

13. Sasaki M, Bharwani S, Jordan P, Joh T, Manas K, Warren A, Harada H, Carter P, Elrod JW, Wolcott M, Grisham MB,Alexander JS:The 3-hydroxy-3-methylglutaryl-CoA reductase inhibitor pravastatin reduces disease activity and inflammation in dextran-sulfate induced colitis. J Pharmacol Exp Ther $305: 78-85,2003$

14. Naito Y, Katada K, Takagi T, Tsuboi H, Isozaki Y, Handa O, Kokura S, Yoshida N, Ichikawa $\mathrm{H}$,Yoshikawa T:Rosuvastatin, a new $\mathrm{HMG}^{-} \mathrm{CoA}$ reductase inhibitor, 
reduces the colonic inflammatory response in dextran sulfate sodium-induced colitis in mice. International Journal of Molecular Medicine 17:997-1004,2006

15. Lee JY, Kim JS, Kim JM, Kim N, Jung HC,Song IS:Simvastatin inhibits NF-kappaB signaling in intestinal epithelial cells and ameliorates acute murine colitis. Int Immunopharmacol 7:241-248,2007

16. Strober W, Fuss IJ,Blumberg RS:The immunology of mucosal models of inflammation. Annu Rev Immunol 20:495-549,2002

17. Neurath MF, Fuss I, Kelsall BL, Stüber E,Strober W:Antibodies to interleukin 12 abrogate established experimental colitis in mice. J Exp Med 182:1281-1290,1995

18. Nieuwenhuis EE, Neurath MF, Corazza N, Iijima H, Trgovcich J, Wirtz S, Glickman J, Bailey D, Yoshida M, Galle PR, Kronenberg M, Birkenbach M,Blumberg RS:Disruption of T helper 2-immune responses in Epstein-Barr virus-induced gene 3-deficient mice. Proc Natl Acad Sci U S A 99:16951-16956,2002

19. Heller F, Fuss IJ, Nieuwenhuis EE, Blumberg RS,Strober W:Oxazolone colitis, a Th2 colitis model resembling ulcerative colitis, is mediated by IL-13-producing NK-T cells. Immunity 17:629-638,2002

20. Suzuki S, Tajima T, Sassa S, Kudo H, Okayasu I,Sakamoto S:Preventive effect of fluvastatin on ulcerative colitis-associated carcinogenesis in mice. Anticancer Res $26: 4223-4228,2006$

21. Jahovic N, Gedik N, Ercan F, Sirvanci S, Yüksel M, Sener G,Alican I:Effects of statins on experimental colitis in normocholesterolemic rats. Scand J Gastroenterol 41:954-962,2006 
22. Liu W, Li WM, Gao C,Sun NL:Effects of atorvastatin on the Th1/Th2 polarization of ongoing experimental autoimmune myocarditis in Lewis rats. J Autoimmun $25: 258-263,2005$

23. Aprahamian T, Bonegio R, Rizzo J, Perlman H, Lefer DJ, Rifkin IR,Walsh K:Simvastatin treatment ameliorates autoimmune disease associated with accelerated atherosclerosis in a murine lupus model. J Immunol $177: 3028-3034,2006$

24. Arora M, Chen L, Paglia M, Gallagher I, Allen JE, Vyas YM, Ray A,Ray P:Simvastatin promotes Th2-type responses through the induction of the chitinase family member Ym1 in dendritic cells. Proc Natl Acad Sci U S A 103:7777-7782,2006

25. Bouma G,Strober W:The immunological and genetic basis of inflammatory bowel disease. Nat Rev Immunol 3:521-533,2003

26. Peluso I, Pallone F,Monteleone G:Interleukin-12 and Th1 immune response in Crohn's disease: pathogenetic relevance and therapeutic implication. World J Gastroenterol $12: 5606-5610,2006$

27. Rea WE, Durrant DC,Boldy DA:Ulcerative colitis after statin treatment. Postgrad Med J 78:286-287,2002

28. McKay A, Leung BP, McInnes IB, Thomson NC,Liew FY:A novel anti-inflammatory role of simvastatin in a murine model of allergic asthma. J Immunol $172: 2903-2908,2004$ 
Ikeda et al., Page 15

29. Menzies D, Nair A, Meldrum KT, Fleming D, Barnes M,Lipworth BJ:Simvastatin does not exhibit therapeutic anti-inflammatory effects in asthma. J Allergy Clin Immunol $119: 328-335,2007$ 


\section{Figure 1}

Prophylactic administration of simvastatin improves the body weight reduction induced by TNBS. A significant decrease in body weight in TNBS-treated mice (NS) was observed. ${ }^{*} \mathrm{p}<0.001$ vs. controls (CO; ethanol-treated mice) Administration (prophylactic protocol) of high-dose (high), but not low-dose (low), simvastatin reduced this decrease in body weight. ${ }^{* *} \mathrm{p}<0.01$ vs. NS

\section{Figure 2}

Prophylactic administration of simvastatin improves the macroscopic lesions induced by TNBS. CO: ethanol-treated mice. NS: TNBS-treated mouse, showing marked edema and shortening of colon length. high: high-dose simvastatin. Note the marked reduction in colitis.

\section{Figure 3}

Prophylactic administration of simvastatin improves the histologic lesions induced by TNBS. (a) Microscopic appearance of colon (H\&E stain; magnification $\times 200$ ). CO: ethanol-treated mice. NS: TNBS-treated mice, showing severe transmural colitis. high: high-dose of simvastatin (prophylactic protocol). Note the marked reduction in colitis. (b) Inflammatory grade. Simvastatin dose-dependently improves the inflammation induced by TNBS. ${ }^{* *} \mathrm{p}<0.001$ vs. NS

\section{Figure 4}

Therapeutic administration of simvastatin shows no effect on body weight reduction. CO; ethanol-treated mice. NS; TNBS-treated mice. High: administration (therapeutic protocol) of high-dose simvastatin.

\section{Figure 5}

Therapeutic administration of simvastatin improves histologic lesions induced by TNBS. CO; ethanol-treated mice. NS; TNBS-treated mice. High; administration (therapeutic protocol) of high-dose simvastatin. ${ }^{*} \mathrm{p}<0.05$

\section{Figure 6}

Prophylactic administration of simvastatin suppresses Th 1 cytokine production induced by TNBS. Colonic lamina propria cells were isolated and stimulated with anti-TCR-B 
and concentrations of INF- $\gamma$, TNF- $\alpha$, IL- 4 and IL- 5 were measured in supernatants. IFN- $\gamma$ release was significantly suppressed in mice receiving high-dose simvastatin. ${ }^{*} \mathrm{p}<0.001$ vs. NS.

\section{Figure 7}

Simvastatin shows no effect on body weight reduction (a) and histologic legions (b) induced by OXA. CO; ethanol-treated mice. NS; OXA-treated mice. High; administration (prophylactic protocol) of high-dose simvastatin. 
Figure 1

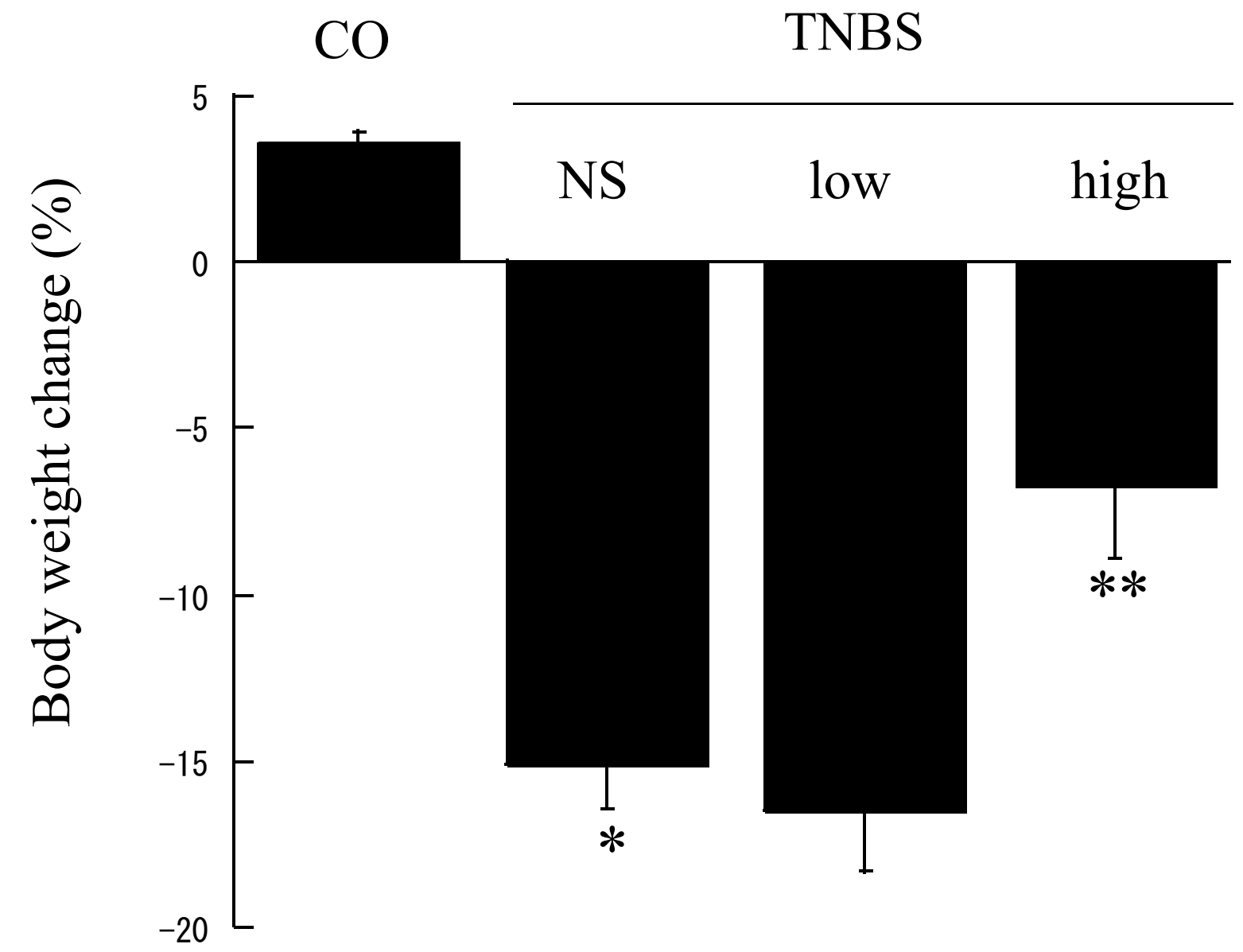


Figure 2
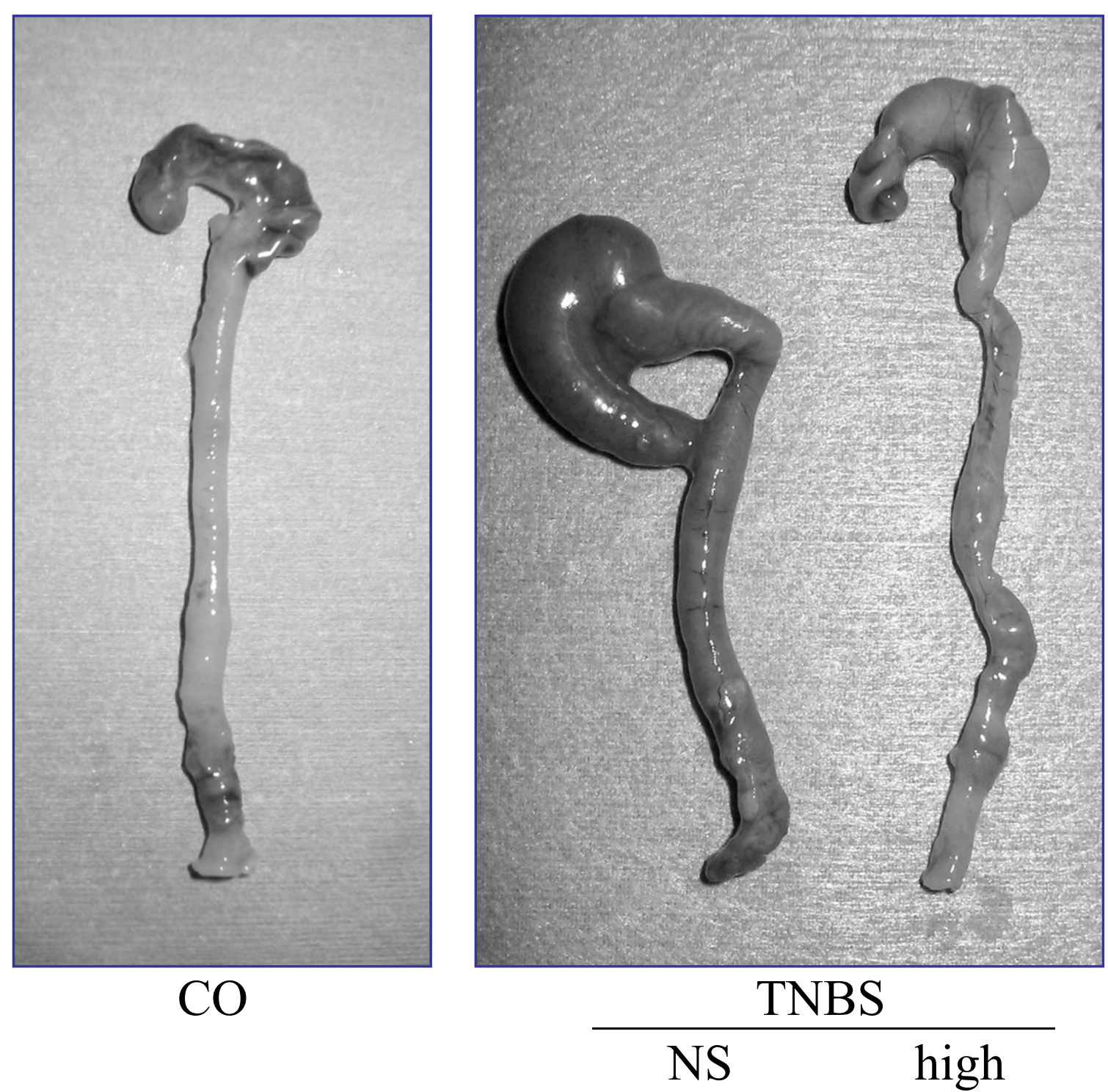
Figure $3 a$

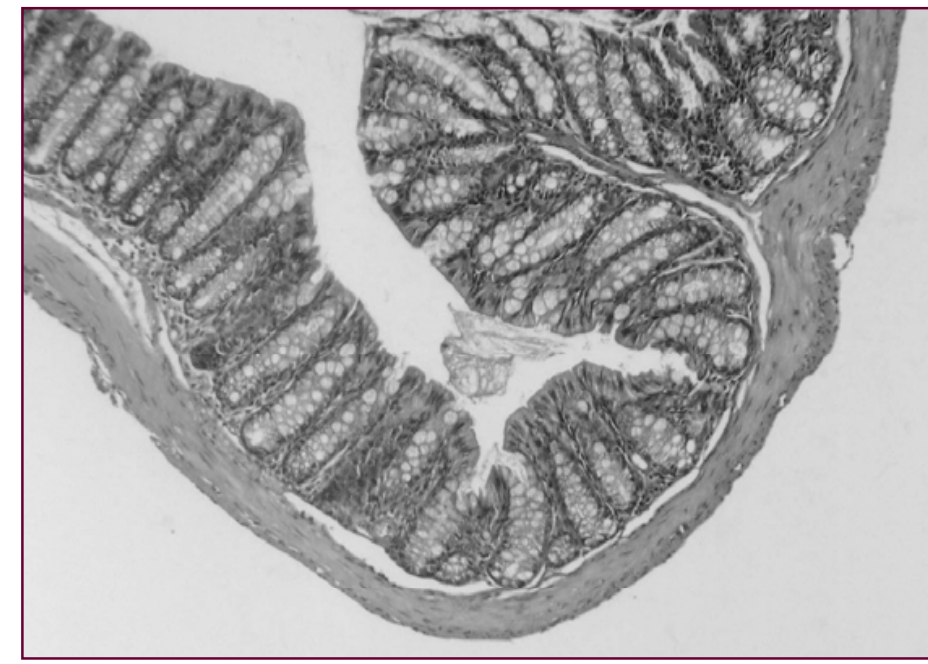

$\mathrm{CO}$
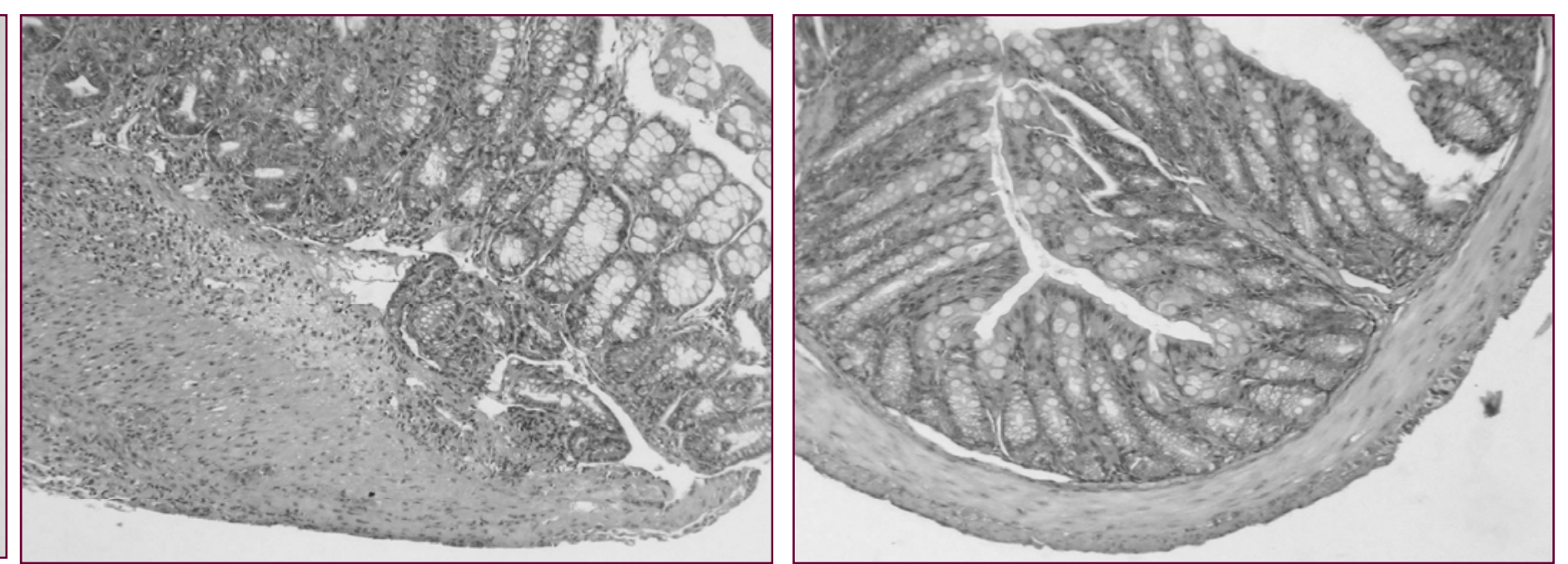

TNBS

NS

high 
Figure $3 b$

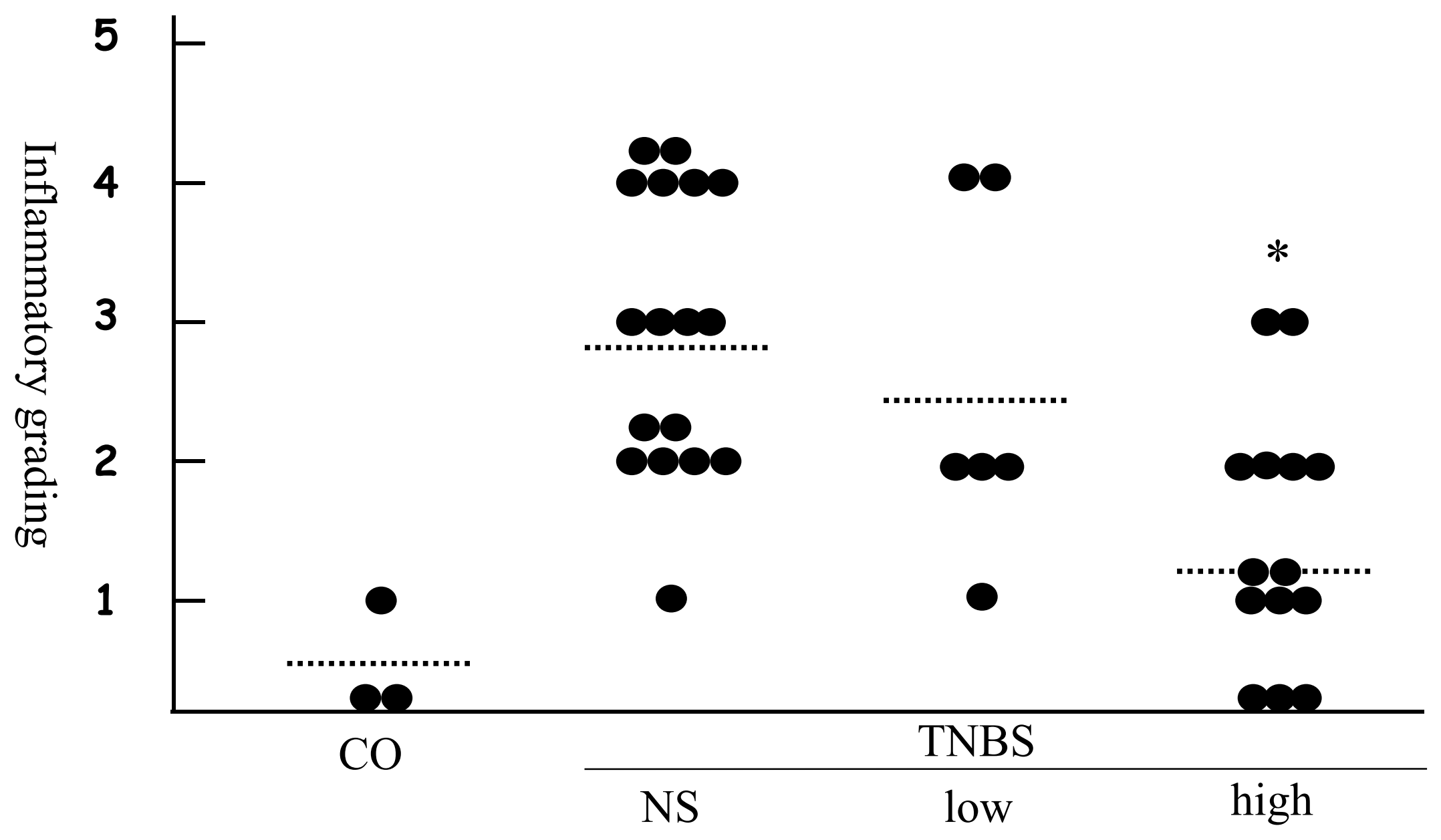


Figure 4

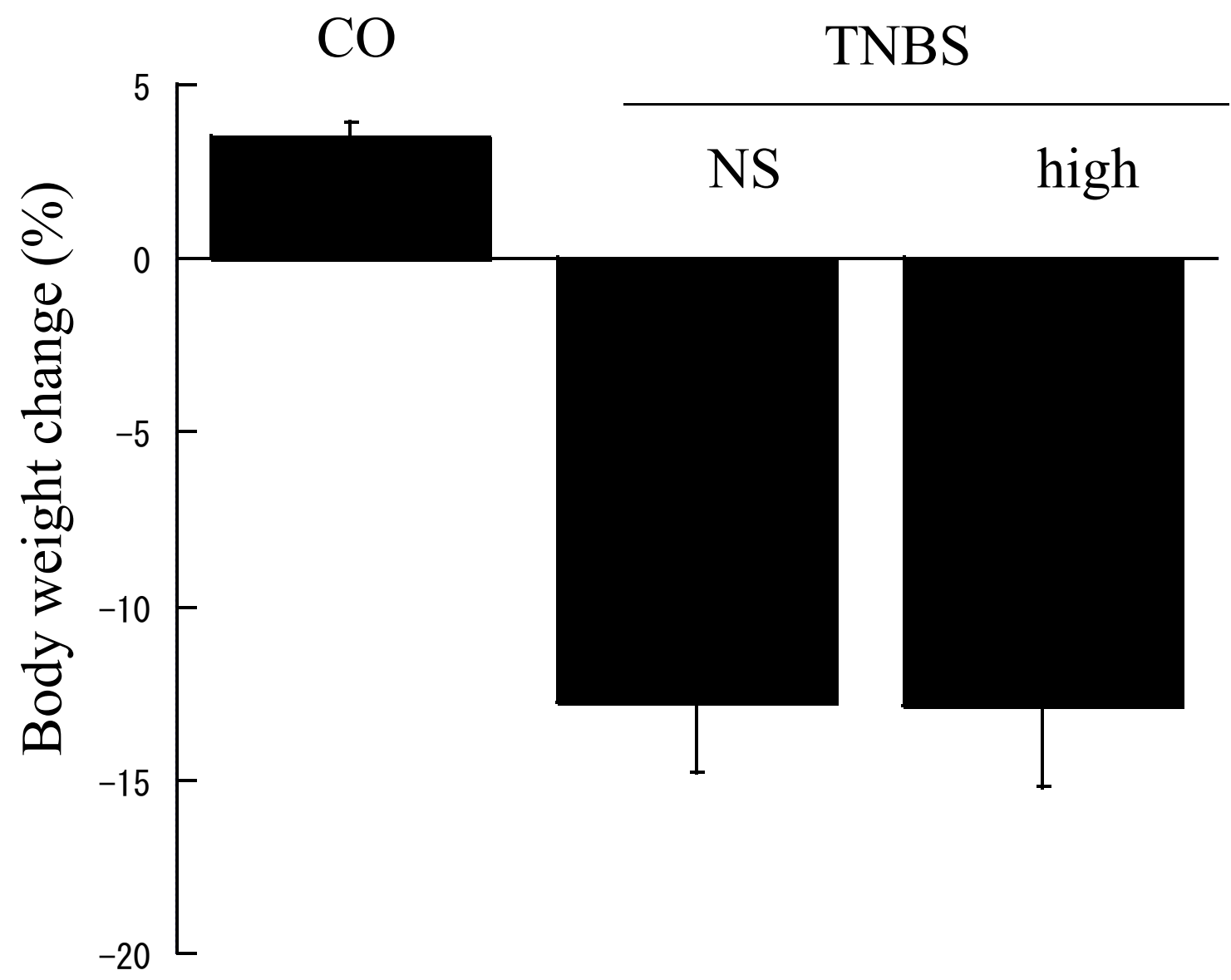


Figure 5

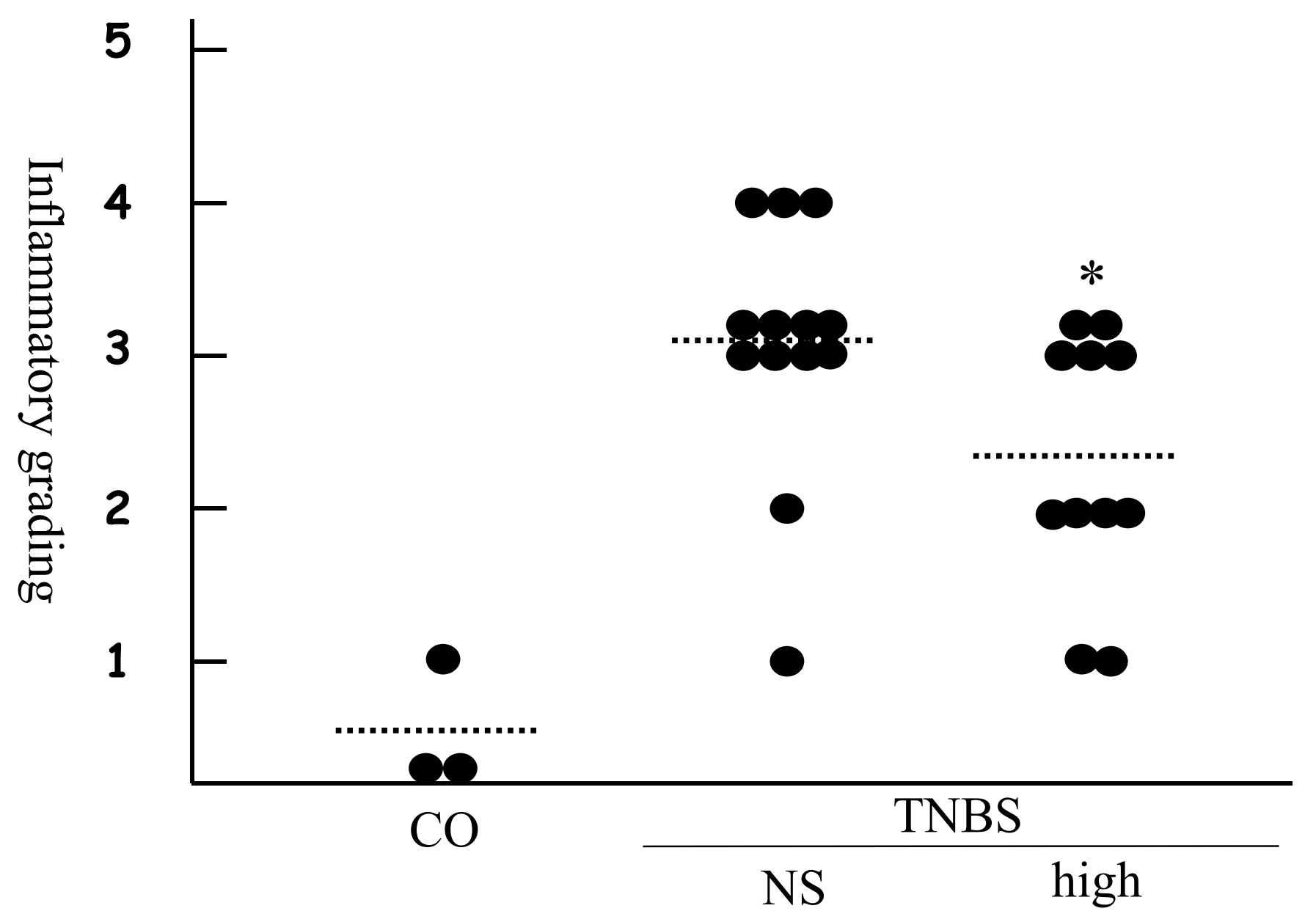


Figure 6

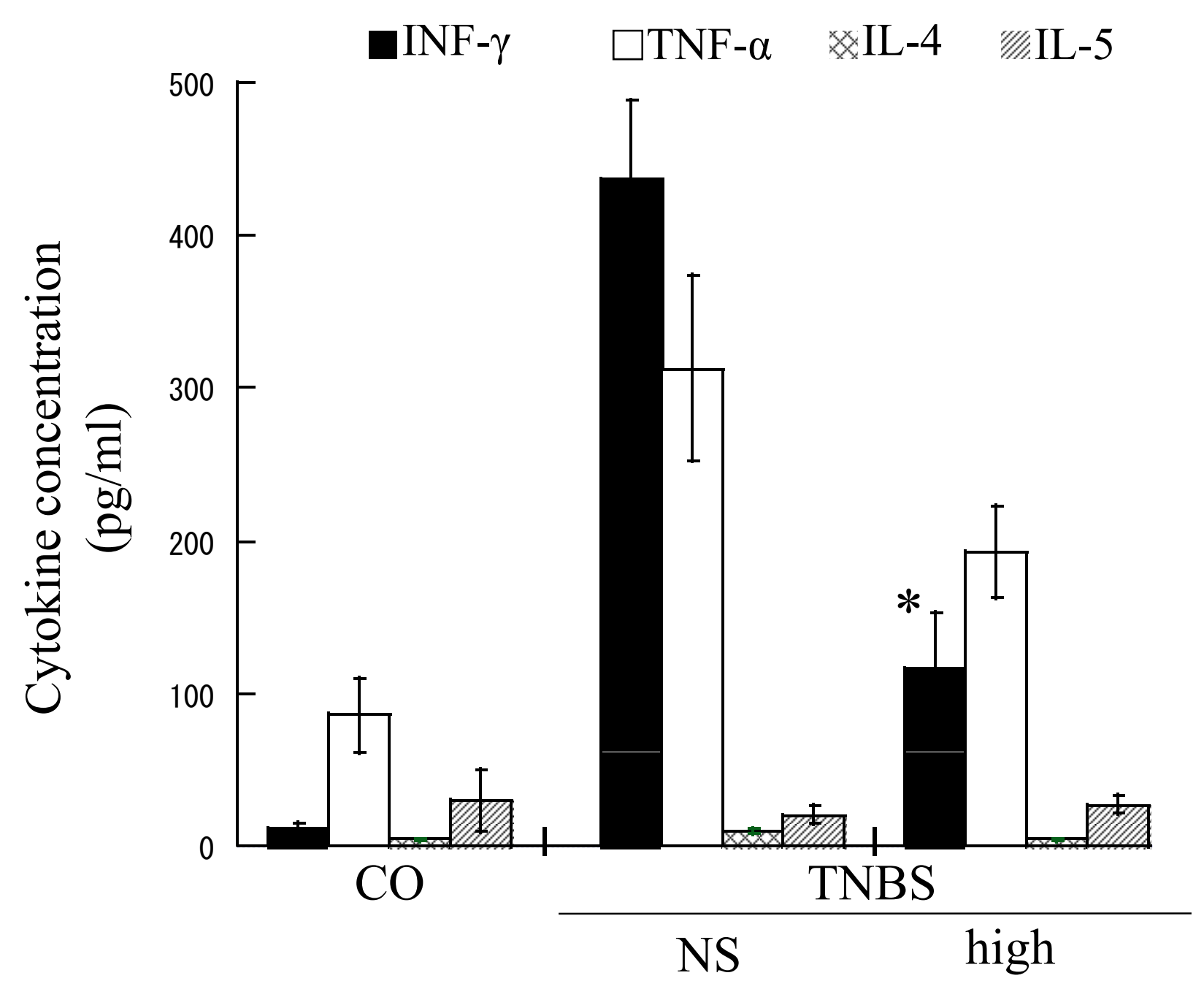


Figure $7 \mathrm{a}$

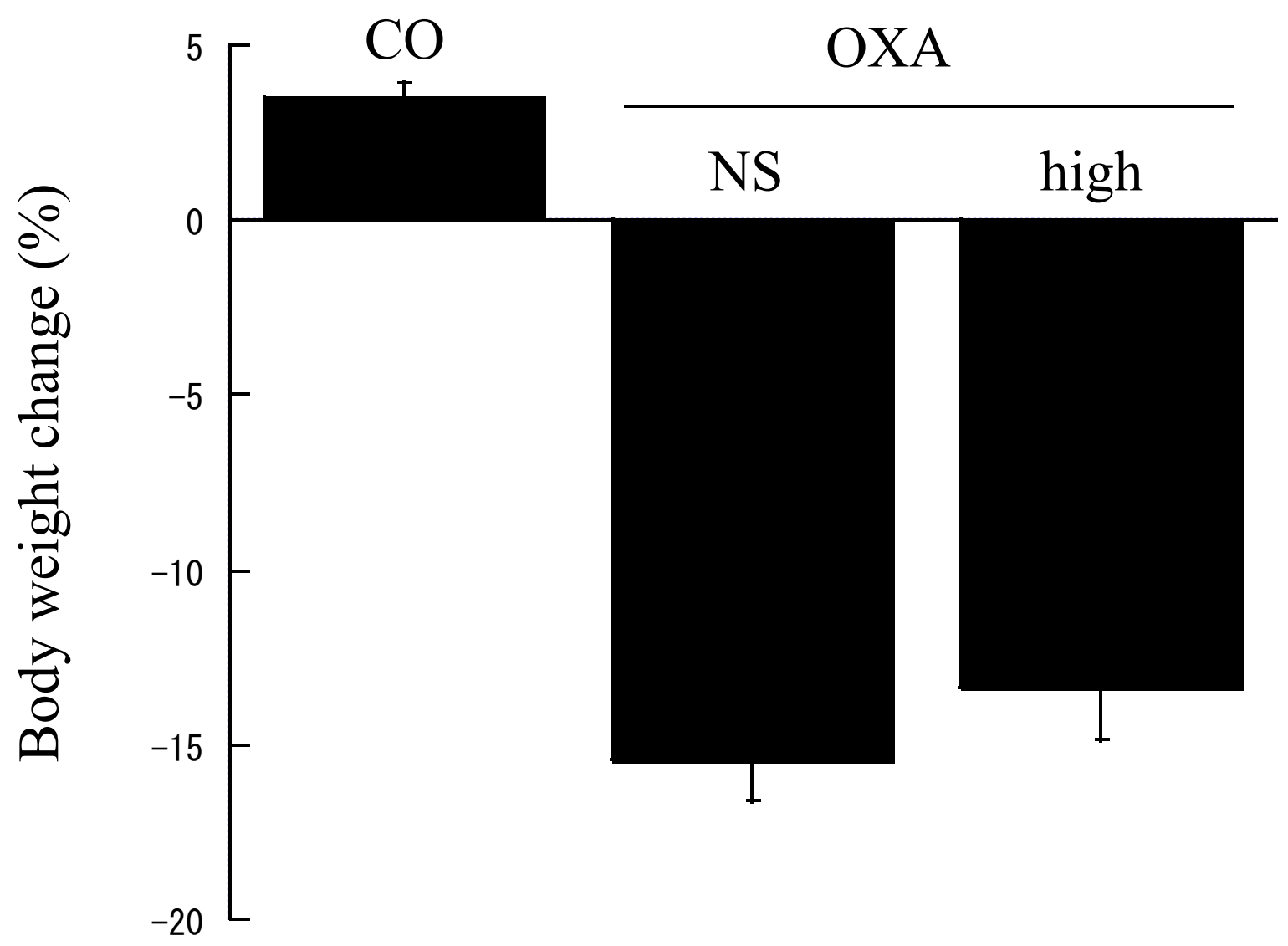


Figure $7 b$

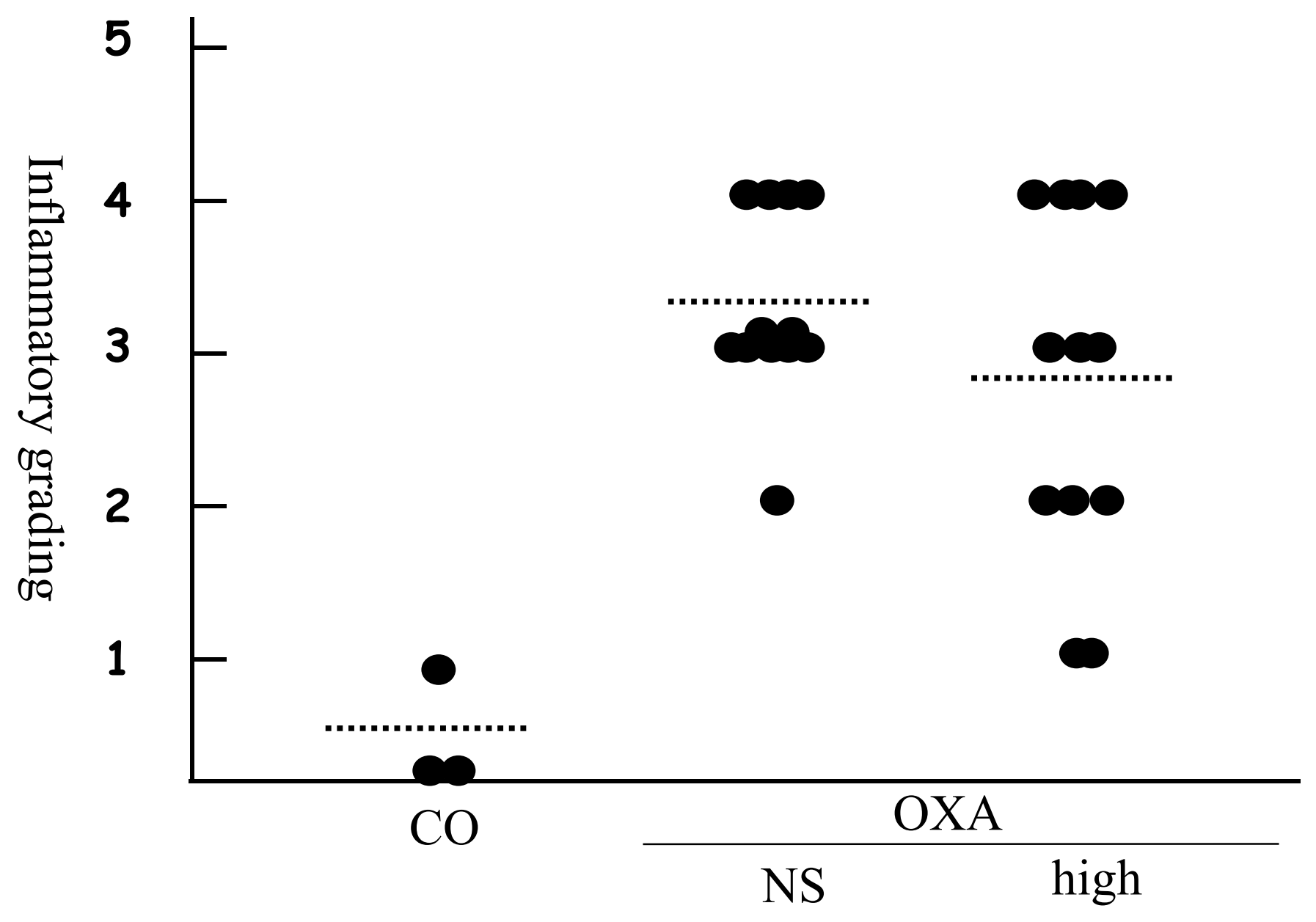

